\title{
EVALUATION OF LOW LEVEL LASER THERAPY ON THE STABILITY OF IMPLANTS USING RESONANCE FREQUENCY ANALYSIS (CLINICAL STUDY)
}

Nada M. Fahmy ${ }^{1} B D S$, Nevein SH. Abdulla ${ }^{2} P h D$, Mervat M. Khalil ${ }^{2} P h D$, Ahmed A. AbdelHakim $^{3} P h D$.

\begin{abstract}
INTRODUCTION: The implant supported overdentures are considered a very successful treatment option for edentulous patients. Low level laser therapy (LLLT) has gained greater awareness in the last decade for implant surgery, reduces postoperative pain after surgery, promotes the osseointegration of implants, particularly, improving stability and enhances new bone formation without causing any tissue destruction. OBJECTIVES: : The aim of this study was the effect of low-level laser therapy on the biostimulation of bone repair by enhancing or accelerating osseointegration through stimulating the expression of osteoblastic phenotype in cells cultured on Titanium specimens.

MATERIALS AND METHODS: 10 patients with age ranged between 45-60 years old were involved in the study. Each patient received 2 implants in the mandibular edentulous ridge at the canine area. The right side acted as study group has received one implant with a Semiconductor diode LASER (type IV) application, while the left acted as control one of same patients having normal loading in left mandibular canine area without LLLT application. All implants osseointegration was assessed by Magnetic Resonance Frequency Analysis to evaluate the implant stability.

RESULTS Resonance Frequency Analysis evaluation revealed great difference in the stability after three months when irradiated with LLLT, implant stability quotient changes were found to be statistically significant between the two studied groups. (P2= <0.001).

CONCLUSIONS: Effect of LLLT on bone remodeling is evident and improves implant stability.

KEYWORDS: dental implants, low level laser therapy, implant stability, Implant supported mandibular overdenture

1. Bachelor student of Oral and Maxillofacial Surgery, Department of Oral and Maxillofacial Surgery, Faculty of Dentistry, Alexandria University, Egypt, Dentist at Ministry of Health, Alexandria Egypt.

2. Professor of Oral and Maxillofacial Surgery, Department of Oral and Maxillofacial Surgery, Faculty of Dentistry, Alexandria University, Egypt.

3. Professor of Prosthodontic, Department of Oral and Maxillofacial Surgery, Faculty of Dentistry, Alexandria University, Egypt
\end{abstract}

\section{INTRODUCTION}

The integration of titanium in bone has been successfully applied in prosthodontics to restore function and esthetics $(1,2)$. Following implant placement, the development of osseointegration is the major factor determining the clinical success (3). Early failure after implantation indicates that the implant failed in the osseointegration stage before loading. Predicting failure can be achieved through clinical testing that evaluates primary stability $(4,5)$. The implant retained overdentures are considered a very successful treatment option for edentulous patients; as they are simple and low cost treatment options related to fixed prosthetics (6).

Implant stability can be seen as a combination of mechanical stability, which is the result of compressed bone holding the implant tightly in place and biological stability, which is the result of new bone cells forming at the site of the implant and osseointegration $(7,8)$.

Resonance Frequency Analysis is a non-invasive testing method that provides objective and reliable measurements of lateral micro-mobility at various stages of the implant process. The method analyzes the first resonance frequency of a small transducer attached to an implant fixture or abutment. The measurement unit is the Implant Stability Quotient (ISQ), which is a scale of measurement developed by Osstell for use with the Resonance Frequency Analysis (RFA) method of measuring implant stability (9-11).

Results are displayed on the instrument as the Implant Stability Quotient (ISQ), which is scaled from 1 to 100 . The higher the number, the greater the stability . Values less than 45 indicate failure of the implant, whereas an ISQ value of about 60-70 indicates success (12).

The laser is a source of non-ionizing radiation which produces thermal, photochemical and non-linear effects on different tissues depending on the type of radiation (13). The concept of biostimulation of wounds by low-level laser therapy (LLLT) is proposed to stimulate wound healing, collagen synthesis, and nerve regeneration (14). The use of low-level laser therapy on the biostimulation of bone repair has been growing steadily and several studies have demonstrated positive results on the healing of bone tissues $(15,16)$.

Therefore, the aim of this study was to evaluate the effect of low-level laser therapy on the biostimulation of bone repair by enhancing or accelerating osseointegration through stimulating the expression of osteoblastic phenotype in cells cultured on Titanium specimens. 


\section{MATERIALS AND METHODS}

The ethical clearance was obtained by the ethical committee before the study began, and the selected patients were informed about the nature of the study and the informed consent was obtained.

\section{Patients}

A total of 10 patients for implant-supported overdenture were included in the study. The patients were selected from those attending the outpatient clinic of the Oral and Maxillofacial Surgery Department, Faculty of Dentistry, Alexandria University.

Patients were divided into 2 groups (study group): 10 patients each received one implant inserted in the right mandibular canine area with LLLT application by a semiconductor diode LASER (type IV) applied to the labial surface of the implant for 2 minutes every 2 days for 2 weeks and (control group):10 patients (same patients) each received one implant inserted in left mandibular canine area without LLLT application. All implants osseointegration was assessed by Magnetic Resonance Frequency Analysis to evaluate the implant stability.

\section{Inclusion criteria}

Completely edentulous patients, adequate oral hygiene and sufficient bone volume to place the planned implant.

\section{Exclusion criteria}

Heavy smokers, medically compromised patients, indication for bone graft at the implant site, current chemotherapy or radiotherapy in facial region and recent extraction sites in anterior mandibular region less than 6 months.

\section{Materials}

-DIO UFII implant system (DIO Implant 66, Centum seoro, Haeundae-gu, Busan 612-020, Korea Tel +82 51745 7777) were used in this study. The size of implants used was standardized $3.8 \times 11.5 \mathrm{~mm}$, placed in the lower anterior canines area. (Fig.1)

-Semi-conductor diode LASER (typeIV) SIROLaser Blue used for LLLT biostimulation. (Fig.2)

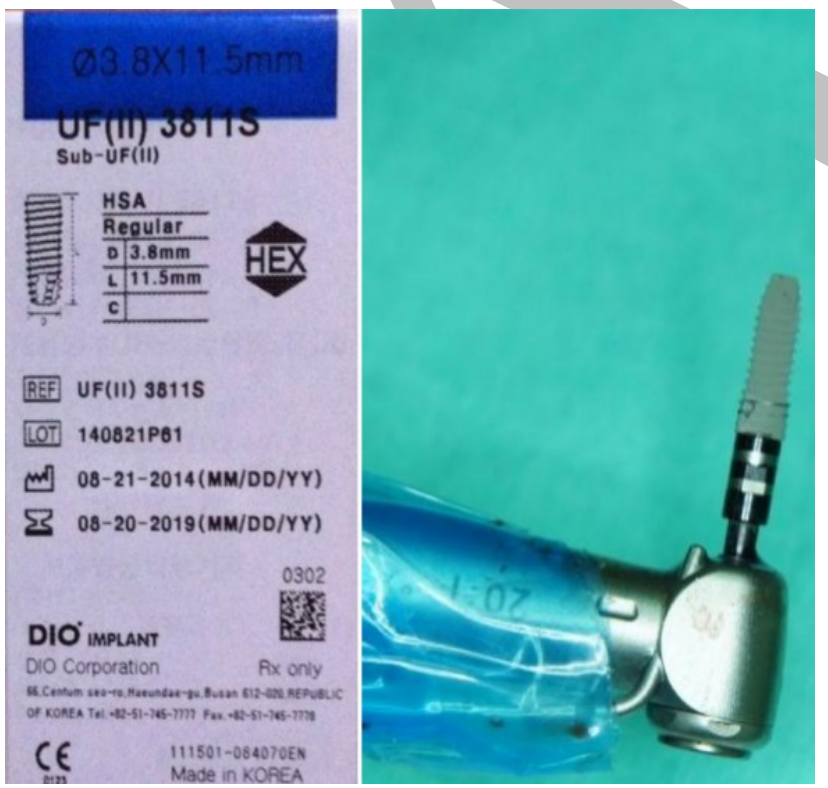

Figure (1): DIO implant size $3.8 \times 11.5 \mathrm{~mm}$.

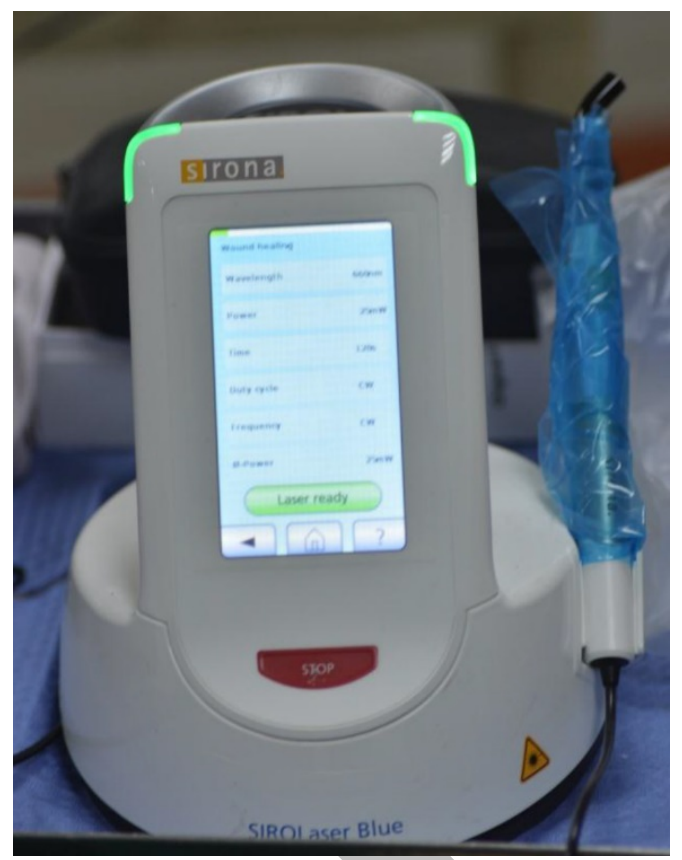

Figure(2):SiroLaser blue unit typeIV used for LLLT biostimulation.

\section{Methods \\ Pre-surgical phase \\ Clinical examination}

The oral mucosa of the edentulous area was examined for color, texture, firmness and thickness. The edentulous area of the operative site was examined for undercuts by palpation through the soft tissue, the height and width of the anterior mandible were estimated by palpation.

Preliminary impressions were made for both upper and lower edentulous ridges. A removable complete denture was then constructed for each patient and relieved at the implant site and the patients were allowed to use it with a soft diet regimen.

\section{Radiographic examination}

Panoramic radiographs were done for all patients to detect the vertical height and condition of bone for suitability of implant placement, any remaining roots or pathology and location of mental foramina.

\section{Surgical phase}

All patients were operated under local anesthesia 2\% lidocaine (1:100000 epinephrine, Novocol Pharmaceutical of Canada, Inc.) using bilateral inferior alveolar nerve block technique in addition to infiltration anesthesia injected to the buccal and lingual mucoperioseteum. An horizontal mid-crestal incision was done from second premolar crossing the midline to the other side second premolar with a bard-parker blade \#15 through the attached gingival slightly lingual to the crest of the ridge (3-4 mm to the crest), blunt dissection of the mucoperiosteal flap with a periosteal elevator was done reflected on the buccal side of the alveolar ridge to expose the ridge buccally and lingually. Duplicated clear acrylic lower dentures with holes into the canines cingulum placed on the bone for accurate determination of implant position and osteotomies were carried out with a starter drill of $1.5 \mathrm{~mm}$ then pilot drill of $2.0 \mathrm{~mm}$ for initial preparation of the implant site, followed by subsequent drills as recommended by the manufacturer with a drilling speed of (800rpm). The smart peg was screwed to the implant fixture, then Osstell device was used holding its probe close to the smart peg without touching it, 
the device beeps displaying the implant stability quotient (ISQ) on its screen. Healing abutments were placed and the mucoperiosteal flap was repositioned by interrupted sutures using 3/0 black silk. (Fig3)
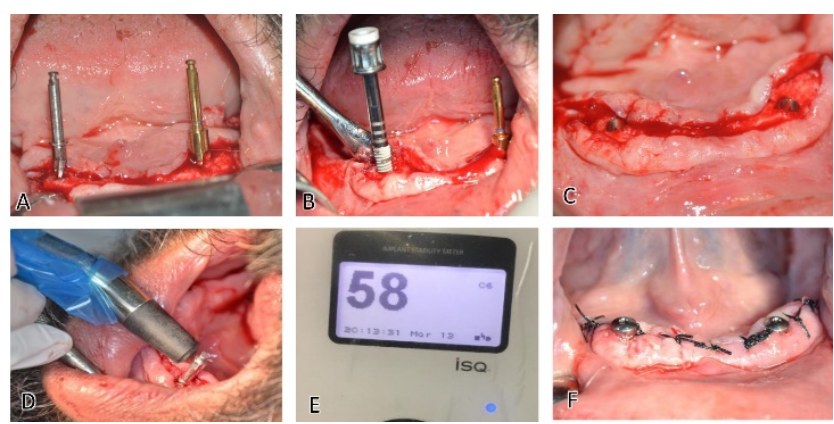

Figure (3):A) $2.0 \mathrm{~mm}$ and $2.7 \mathrm{~mm}$ diameter drills used to mark osteotomy sites. B) Implants inserted using a ratchet. C) An elevated mucoperiosteal flap with implants placed in drilled sites. D) Measurement probe held close to the smart peg in a mesiodistal direction without contact. E) ISQ value displayed on the screen of osstell. F) Healing abutments were placed and mucoperiosteal flap was repositioned

\section{Postsurgical phase}

Application of laser: Group I, each right mandibular implant at the canine area of each patient was submitted to 8 sessions of LLLT Semi-conductor diode LASER (type IV) intra orally with wavelength of $660 \mathrm{~nm}$ was set to the power of $25 \mathrm{~mW}$ and directed to the labial surface of the implant (in non contact mode) $5 \mathrm{~mm}$ away from the gum, started from the surgery day, the LLLT application was repeated every $48 \mathrm{hrs}$ for 2 weeks for 2 minutes. Group II implants were not subjected to any LLLT.

\section{Postoperative instructions including:}

Extra-oral ice packs during the first day every one hour and maintain daily routine oral hygiene after surgery and patients were instructed to eat a soft diet for 7 days.

All patients received postoperative medications including:

Broad spectrum oral antibiotics : amoxicillin 875m / clavulanic acid 125mg (Augmentin 1gm Tablets, Medical Union Pharmaceuticals (MUP), GlaxoSmithKline, Cairo, Egypt) in a dose of one capsule every twelve hours for a week.

Non-steroidal anti-inflammatory drugs Ibuprofen 400 mg (Brufen tablet 400mg Abbott, Cairo, Egypt) at a dose of one tablet every 8 hours for four days.

Warm chlorhexidine gluconate solution (Hexitol mouth wash, Arab Drug Co., Cairo, Egypt) as a mouthwash for a period of 2 weeks to enhance plaque control.

\section{Follow up phase}

\section{Clinical evaluation}

After implant placement, each patient was evaluated clinically for:

Presence of pain or infection at a period of one week.

Stability of implants assessment was done using RFA was repeated two weeks, one month and three months intervals for both groups. ISQ measurements were made at two directions (bucco-lingual and mesio-distal).

\section{Radiographic evaluation}

Periapical x-ray films were performed post-operative at the third month to find the presence of any pathological lesion and evaluating any bone loss around the implants.

\section{Prosthetic phase}

On the third month after implant placement, the final prosthesis was delivered over the locator abutments and functional loading was applied on the osseointegrated implants. (Fig 4)
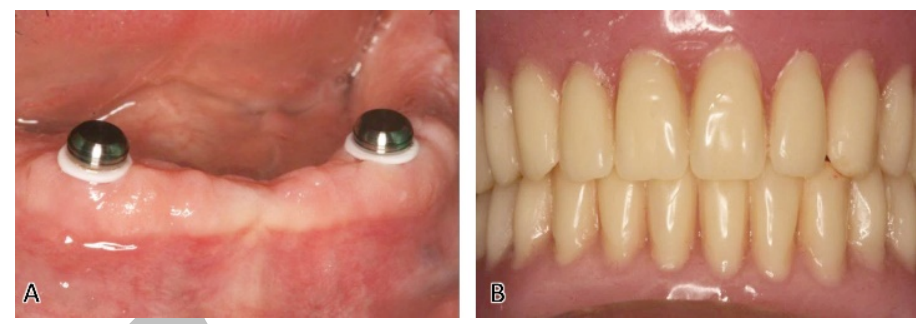

Figure (4):A) White block out spacer ring and metal cap with black processing male secured on each locator abutment. B) Overdenture at centric occlusion.

\section{Statistical analysis of the data (17)}

Data were fed to the computer and analyzed using IBM SPSS software package version 20.0. (Armonk, NY: IBM Corp) (18) Qualitative data were described using number and percent. The Kolmogorov-Smirnov test was used to verify the normality of distribution Quantitative data were described using range (minimum and maximum), mean, standard deviation and median. Significance of the obtained results was judged at the $5 \%$ level. The used tests were Student t-test

For normally distributed quantitative variables,to compare between two studied groups ANOVA with repeated measures

For normally distributed quantitative variables, to compare between more than two periods or stages, and Post Hoc test (Bonferroni adjusted) for pairwise comparisons

\section{RESULTS}

All patients were free from any systemic disease that can compromise implant success. Their ages ranged from 45 to 60 years with mean age of 52 years of both sexes ( 9 males and 1 female).

Ten implants assigned to the study group were inserted in the right mandibular canine region having diameters of $3.8 \mathrm{~mm}$ and length of $11.5 \mathrm{~mm}$. Ten implants assigned to the control group were inserted in the left mandibular canine region having diameters of 3.8 and lengths of $11.5 \mathrm{~mm}$.

All patients were followed up after implant placement every 48 hours for 2 weeks for Low Level Laser Therapy application for each study group implants, and followed up for 2 weeks, one month and 3 months intervals for both study and control groups using Osstell for the ISQ values. Results were registered as regards clinical and radiographic evaluation for 3 months.

\section{Clinical results}

\section{Pain, infection and/or swelling}

Pain was evaluated one week post-surgically after implants placement to detect pain severity according to the Numerical Rating scale from (0-10) where $0=$ no pain and $10=$ worst pain (19). Control patients were evaluated for the presence of pain. Five had no pain at all, and the other five patients suffered pain till the end of the first week after surgery with a score mean of $1.20 \pm 0.42$. Same ten Patients of the study group received ten implants with no pain at all till the end of first which was scored 0 . 
All patients experienced mild to moderate pain at the surgical sites. Two had worst pain and showed moderate oedema which subsided totally by the end of 2nd postsurgical day, and one which subsided totally by the end of 1 st post-surgical day. The Oedema percentage was $70 \%$ moderate and $30 \%$ mild. No post-operative, infection or nerve injury. (Table 1) All patients continued the follow up period without any signs of infection, gingivitis, or periimplantitis.

Table (1):Distribution of studied cases according to pain severity, pain duration, edema and infection following implant placement procedures $(\mathrm{n}=10)$

\begin{tabular}{||c|c|c||}
\hline & No. & $\%$ \\
\hline Infection & \multicolumn{2}{|c||}{} \\
Absent & 10 & 100.0 \\
\hline Pain duration & \multicolumn{2}{|c||}{$1.0-2.0$} \\
Min. - Max. & \multicolumn{2}{|c||}{$1.20 \pm 0.42$} \\
Mean \pm SD. & \multicolumn{2}{|c|}{1.0} \\
Median & \multicolumn{2}{|c|}{} \\
\hline Oedema & 7 & 70.0 \\
Mild & 3 & 30.0 \\
Moderate & & \\
\hline
\end{tabular}

Implant stability quotient (ISQ)

Implant Stability Quotients measured by Resonance Frequency Analysis for each implant during the postoperative three months. Measurements were taken in a bucco-lingual and mesio-distal directions around the implants immediately after implant placement and on the 2nd week, 1st month and 3rd months. A measurement of Osstell is displayed as implant stability quotient (ISQ) from 1 to 100 , where 100 signify the highest implant stability.

ISQ values for the study group in bucco-lingual direction. The ISQ values decreased from the day of placement with a minimum recorded value of 49.0 and a maximum recorded value of 70.0 and mean ISQ value of $(57.50 \pm 6.87)$, to a minimum value of 44.0 at the 2 weeks and a maximum value of 61.0 and a mean value of (52.40 \pm 5.62), a minimal decrease in the ISQ values at the first month to be with a minimum recorded value of 42.0 and a maximum recorded value of 58.0 and a mean ISQ value of $(49.60 \pm 5.64)$. ISQ values were increased during the rest of the study period to end up at the 3rd month with a minimum recorded value of 67.0 and a maximum recorded value of 83.0 and a mean ISQ value of $(74.40 \pm 4.35)$. Difference was statistically significant at $5 \%$ level of significance.

ISQ values for the same study group during same periods in mesio-distal direction were at the day of placement with mean ISQ value of $(58.90 \pm 6.81)$ that decreased to be at the first month with a mean ISQ value of $(51.30 \pm 5.91)$ and then increased to be at the 3rd month with a mean ISQ value of $(76.50 \pm 4.60)$ which was also statistically significant.

Results of ISQ for the control group in bucco-lingual direction denotes a wide variation in the stability implant difference that decreased from the day of placement with a minimum recorded value of 51.0 and a maximum recorded value of 71.0 of a mean ISQ value $(57.90 \pm 6.64)$ to the first month with a minimum recorded value of 40.0 and a maximum recorded value of 52.0 and a mean ISQ value of $(46.60 \pm 4.58)$ and increased during the rest of the study period to be at the 3rd month with mean ISQ value (69.60 \pm 4.01).

Same control group during same periods showed ISQ in mesio-distal direction that started with a mean value of $(59.30 \pm 6.75)$ at the day of placement to a mean value decrease of $(47.90 \pm 5.30)$ at the first month follow-up, then increased during the rest of study to be at the 3rd month with a mean value of (71.20 \pm 4.49$)$. Difference was statistically significant at $5 \%$ level of significance. (Table 2) (Fig. 5)

Table (2):Comparison (ISQ) between the different studied periods according to Bucco- Lingual

\begin{tabular}{|c|c|c|c|c|}
\hline $\begin{array}{c}\text { Bucco- } \\
\text { Lingual } \\
\text { direction of } \\
\text { study group }\end{array}$ & Day 0 & 2 weeks & 1 month & $\begin{array}{c}3 \\
\text { months }\end{array}$ \\
\hline $\begin{array}{l}\text { Min. - } \\
\text { Max. }\end{array}$ & $49.0-70.0$ & $44.0-61.0$ & $42.0-58.0$ & $\begin{array}{c}67.0- \\
83.0\end{array}$ \\
\hline $\begin{array}{l}\text { Mean } \pm \\
\text { SD. }\end{array}$ & $\begin{array}{c}57.50 \pm \\
6.87\end{array}$ & $\begin{array}{c}52.40 \pm \\
5.62\end{array}$ & $\begin{array}{c}49.60 \pm \\
5.64\end{array}$ & $\begin{array}{c}74.40 \pm \\
4.35\end{array}$ \\
\hline Median & 56.0 & 52.0 & 49.50 & 74.50 \\
\hline$F(p)$ & \multicolumn{4}{|c|}{$229.046^{*}\left(<0.001^{*}\right)$} \\
\hline $\begin{array}{l}\text { Mesio-Distal } \\
\text { direction of } \\
\text { study group }\end{array}$ & Day 0 & 2 weeks & 1 month & $\begin{array}{c}3 \\
\text { months }\end{array}$ \\
\hline $\begin{array}{l}\text { Min. - } \\
\text { Max. }\end{array}$ & $50.0-71.0$ & $46.0-62.0$ & $44.0-60.0$ & $\begin{array}{c}68.0- \\
85.0\end{array}$ \\
\hline $\begin{array}{l}\text { Mean } \pm \\
\text { SD. }\end{array}$ & $\begin{array}{c}58.90 \pm \\
6.81\end{array}$ & $\begin{array}{c}54.10 \pm \\
5.80\end{array}$ & $\begin{array}{c}51.30 \pm \\
5.91\end{array}$ & $\begin{array}{c}76.50 \pm \\
4.60\end{array}$ \\
\hline Median & 58.0 & 53.50 & 50.0 & 76.50 \\
\hline$F(p)$ & \multicolumn{4}{|c|}{$397.034^{*}\left(<0.001^{*}\right)$} \\
\hline $\begin{array}{l}\text { Bucco- } \\
\text { Lingual } \\
\text { direction of } \\
\text { control } \\
\text { group }\end{array}$ & Day 0 & 2 weeks & 1 month & $\begin{array}{c}3 \\
\text { months }\end{array}$ \\
\hline $\begin{array}{l}\text { Min. - } \\
\text { Max. }\end{array}$ & $51.0-71.0$ & $43.0-59.0$ & $40.0-52.0$ & $\begin{array}{c}65.0- \\
78.0\end{array}$ \\
\hline $\begin{array}{l}\text { Mean } \pm \\
\text { SD. }\end{array}$ & $\begin{array}{c}57.90 \pm \\
6.64\end{array}$ & $\begin{array}{c}50.40 \pm \\
5.48\end{array}$ & $\begin{array}{c}46.60 \pm \\
4.58\end{array}$ & $\begin{array}{c}69.60 \pm \\
4.01\end{array}$ \\
\hline Median & 57.0 & 50.50 & 47.0 & 68.0 \\
\hline $\mathbf{F}(\mathbf{p})$ & \multicolumn{4}{|c|}{$192.009^{*}\left(<0.001^{*}\right)$} \\
\hline $\begin{array}{l}\text { Mesio-Distal } \\
\text { direction of } \\
\text { control } \\
\text { group }\end{array}$ & Day 0 & 2 weeks & 1 month & $\begin{array}{c}3 \\
\text { months }\end{array}$ \\
\hline $\begin{array}{l}\text { Min. - } \\
\text { Max. }\end{array}$ & $52.0-72.0$ & $45.0-62.0$ & $41.0-55.0$ & $\begin{array}{c}66.0- \\
80.0\end{array}$ \\
\hline $\begin{array}{l}\text { Mean } \pm \\
\text { SD. }\end{array}$ & $\begin{array}{c}59.30 \pm \\
6.75\end{array}$ & $\begin{array}{c}52.70 \pm \\
5.79\end{array}$ & $\begin{array}{c}47.90 \pm \\
5.30\end{array}$ & $\begin{array}{c}71.20 \pm \\
4.49\end{array}$ \\
\hline Median & 57.50 & 52.0 & 48.0 & 71.50 \\
\hline $\mathbf{F}(\mathbf{p})$ & \multicolumn{4}{|c|}{$221.125^{*}\left(<0.001^{*}\right)$} \\
\hline
\end{tabular}


Comparison of Mean implant stability in bucco-lingual direction upon fixation at base line and at each postoperative periodic test for the study group showed a significant decrease in stability during the first two weeks with a mean difference of $\downarrow 5.1$ and another significant decrease with a mean difference of $\downarrow 7.9$ at the first month. The same group showed a greater real increase at 3rd month with a mean difference of $\uparrow 16.9$, Difference was statistically significant at $\mathrm{p} 1=<0.001^{*}$. The control group showed a significant decrease in stability at the 2 weeks and the mean difference was $\downarrow 7.5$, and a significant decrease at the first month of a mean difference $\downarrow 11.3$, followed by an increase in stability at $3 \mathrm{rd}$ month with a mean difference of $\uparrow 11.7$, Difference was statistically significant at $\mathrm{p} 1=$ $<0.001 *$.Comparison of Mean differences in stability between study and control groups in bucco-lingual direction was only significant at 3rd month with a p2 $=0.019 *$. (Table 3)

Table (3): Comparison (ISQ) of the mean differences of Bucco-Lingual and Mesio-Distal direction of both groups between base line and each other time interval.

\begin{tabular}{|c|l|c|c|c|c||}
\hline \multicolumn{2}{|c|}{} & Day 0 & 2 weeks & $\begin{array}{c}\text { 1 } \\
\text { month }\end{array}$ & $\begin{array}{c}\text { 3 } \\
\text { months }\end{array}$ \\
\hline \multirow{2}{*}{ Study } & Mean diff. & & $\downarrow 5.1$ & $\downarrow 7.9$ & $\uparrow 16.9$ \\
\cline { 2 - 6 } & $\mathbf{p}_{1}$ & & $0.001^{*}$ & $<0.001^{*}$ & $<0.001^{*}$ \\
\hline \multirow{2}{*}{ Control } & Mean diff. & & $\downarrow 7.5$ & $\downarrow 11.3$ & $\uparrow 11.7$ \\
\cline { 2 - 6 } & $\mathbf{p}_{1}$ & & $<0.001^{*}$ & $<0.001^{*}$ & $<0.001^{*}$ \\
\hline \multicolumn{2}{|c|}{$\mathbf{p}_{2}$} & 0.896 & 0.431 & 0.208 & $0.019^{*}$ \\
\hline \multirow{2}{*}{ Study } & Mean diff. & & $\downarrow 4.8$ & $\downarrow 7.6$ & $\uparrow 17.6$ \\
\cline { 2 - 6 } & $\mathbf{p}_{1}$ & & $<0.001^{*}$ & $<0.001^{*}$ & $<0.001^{*}$ \\
\hline \multirow{2}{*}{ Control } & Mean diff. & & $\downarrow 6.6$ & $\downarrow 11.4$ & $\uparrow 11.9$ \\
\cline { 2 - 6 } & $\mathbf{p}_{1}$ & & $<0.001^{*}$ & $<0.001^{*}$ & $<0.001^{*}$ \\
\hline \multicolumn{2}{|c|}{$\mathbf{p}_{2}$} & 0.896 & 0.596 & 0.192 & $0.018^{*}$ \\
\hline
\end{tabular}
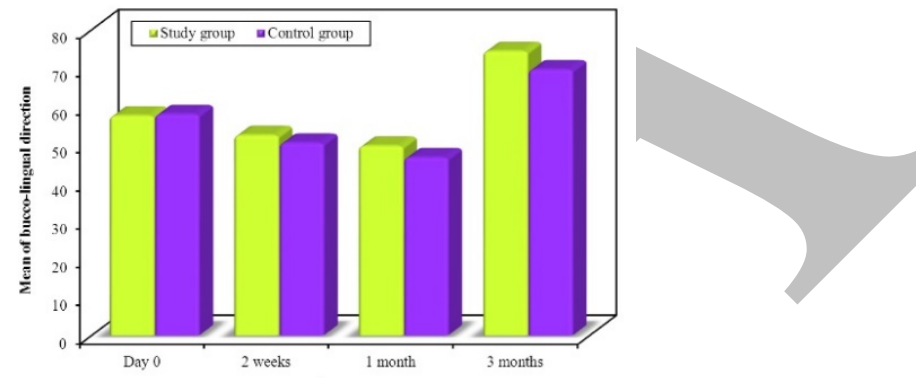

A

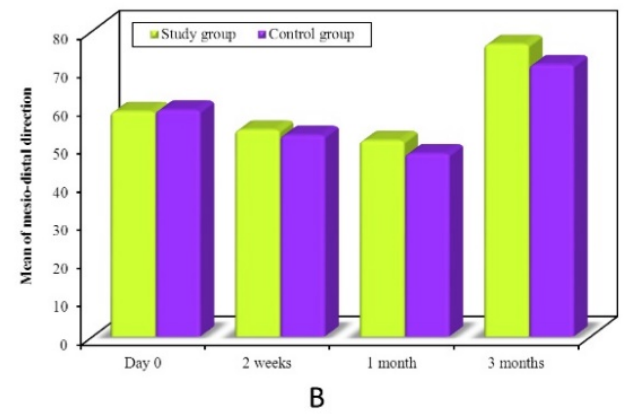

Figure (5):A) Comparison of (ISQ) between the different studied periods of both groups according to Bucco-Lingual direction $(n=10)$. B) Comparison of (ISQ) between the different studied periods of both groups according to Mesio-Distal direction $(\mathrm{n}=10)$.
Comparison of Mean implant stability in mesio-distal direction upon fixation at base line and at each postoperative periodic test for both study and control group,trend of time-related change in stability was similar to that in bucco-lingual direction. However the difference between the two groups in mesio-distal direction was only significant at the end of study at 3rd month with a p2 = 0.018*. (Table 3)

\section{Radiographic evaluation}

Periapical x-rays films were performed after 3 months for the evaluation of cases showed no apical pathology or bone loss around the implants.

\section{DISCUSSION}

Osseointegration is defined as direct connection between bone and implant surface, is the result of bone formation between bone and implant surface (20). Implant stability can be defined as the absence of clinical mobility under a specific load, which depends on the contact between implant surface and the bone surrounding the implant and is determined by the pressure exerted by the implant when inserted into the prepared socket $(1,2)$.

Primary stability is one of the most favoring factors of osseointegration. It requires the absence of micromovements during the early stage of bone healing and remodeling (21). Primary stability is obtained by mechanical fixation of the implant with bone. Measurement of changes in the implant stability indicates progress of Osseointegration.

Low-Level Laser Therapy (LLLT) has been applied in several clinical situations, such as orthodontic treatment, alveolar repair after tooth extraction, bone fracture healing, and osseointegration of dental implants as an adjunct therapy. Its advantages in implant dentistry include increased haemostasis, reduced swelling, reduced infection, and reduced pain postoperatively (22). Different laser applicators with different wavelengths have been introduced in dental field.

All included patients were subjected to delicate surgery using the delayed surgical placement and loading protocols. As low speed high torque hand piece was used for the preparation of the implant bed, and the drilling was performed under irrigation using cold normal saline for proper cooling and to avoid overheating of the bone tissue which would compromise osseointegration. This was supported by Strbac et al (23) in 2012. This also matches findings obtained by Lee et al (24) in 2012 and Augustin et al (25).

Regarding the clinical evaluation in the study throughout the follow-up period which was extended up to three months, the use of LLLT in the present study contributed to a more comfortable and less painful post operative healing phase especially in first week as no patients reported any pain. Five patients of the control group, had higher values (scores1-2) of subjective pain. This was supported by many studies $(16,26)$. Especially Khadra et al (14), Who explained that LLLT enhances bone healing and contributes to much less discomfort experienced by the patient following surgical treatment. And none of the patients showed any persistent tenderness, infection or swelling throughout the follow up period. This 
could be attributed to the high biocompatibility and excellent tissue response to biomedical titanium alloy.

Regarding the implant mobility, no clinical mobility was detected in any of the implants throughout the follow-up period. This was confirmed by the radiographic evaluation that revealed intimate bone-implant contact in all implants. The absence of implant mobility is one of the most important criteria for implant success in accordance with McKinney et al (27).

In the present study ISQ measures was used to evaluate the implant stability after LLLT, allowing the testing of the implant stability from a bucco-lingual and mesio-distal direction. According to Ersanli et al. (28), and Zix et al. (29), single RFA measurement of an implant is of limited clinical value. The present results are based on repeated measurements over a period of three months for comparative purpose. Implant stability was measured at four intervals for each implant. Garcia-Morales et al (30) showed that LLLT has an effect on implant stability during osseointegration stages by means of RFA, the results cannot be directly compared to any other study. The outcome of an implant stability analysis is highly dependent on the type of test used and the direction and type of the applied force (31). RFA measurements essentially apply a bending load, which mimics the clinical load and direction and provides macroscopic information about the stiffness of the implantbone interface (31). The RFA technique has been extensively used in experimental and clinical research over the last 10 years for assessing primary stability, determining the adequate period of osseointegration before loading the implant, verifying whether sufficient stability has been attained in second-stage surgery, following-up the stability during the osseointegration process, as well as monitoring high-risk implants $(22,32,33)$.

Concerning ISQ measurements during the initial follow up period showed a little dropped values at the 2 nd week for study groups and considerable drop at the same period for control groups, followed by a significant drop in stability in both control and study groups at the 4th week, which were similar to results of Garcia-Morales et al. (30) has found a significant drop in stability from the 10th day to the 6th week in the irradiated group during the osseointegration period followed by a rise in the next weeks.

At the third month, the ISQ measurements for the study group showed a greater real increase in both mesiodistal and bucco-lingual direction with a mean value of $(76.50 \pm 4.60)$ and $(74.40 \pm 4.35)$ respectively, when compared to the ISQ increased measurments of control group at same period, the mean values of both mesio-distal and the bucco-lingual directions were $(71.20 \pm 4.49)$ and (69.60 \pm 4.01). The study group had statistically significantly higher values after ten weeks of implants placement and LLLT doses, this could be attributed to the explanation by Walsh et al (22), who proposed the mechanism of role of LLLT in early bone healing to rely mainly upon stimulation of osteoblast precursor cell proliferation and increasing the number of osteoblastic cells, with a subsequent increase in bone formation. LLLT also increases local blood flow, enhancing the supply of circulating cells, nutrition, oxygen, and inorganic salts to the bone defect (34). This results confirmed the findings of Kim et al (35) who found the average of ISQ values for the 12th week of the LLLT and control groups were 73.3 \pm 6.6 and 65.7 \pm 9.7 , respectively. The LLLT group had statistically significantly higher values.

The present study showed significant difference in stability of implants with or without LLLT during the study periods and showed biostimulatory effects of LLLT reported to modulate inflammation and enhance bone healing. This agreed with Khadra (36), who found in a group of rabbits with implants placed in the tibia, that the implants treated with LLLT showed higher osseointegration than the control group of rabbits. At eight weeks after implantation, the LLLT group had higher measured values than the control group in the tensile pullout test and in histomorphometric analysis. Guzzardella et al. (37), who found after six weeks of implantation in the fibulas, rabbits that were treated with LLLT had higher measured osseointegration than those that were not treated with LLLT. However, in contrast, some reports have shown that LLLT has no beneficial effect or even has negative effects on osseointegration, Pereira et al. (38) placed implants in the fibula of rabbits, and the analysis showed that the LLLT group and control group did not have statistically significant differences.

\section{CONCLUSION}

Within the limitations of this study, the following conclusions can be addressed:

1. Anchorage of dental implants to bone changes by time, starting by a decrease during the first four weeks and improves at the third month. It reflects the biomechanical characters of the investing bone.

2. Application of LLLT improves bone reaction and resulting implant stability.

3. Effect of LLLT on bone remodeling is definite but takes time to be evident

4. Initial thickness of investing bone has its effect on implant stability.

\section{CONFLICT OF INTEREST}

The authors declare that they have no conflicts of interest.

\section{REFERENCES}

1. Farre-Pages N, Auge-Castro ML, Alaejos-Algarra F, Mareque-Bueno J, Ferres-Padro E, Herrnandez-Alfaro F. Relation between bone density and primary implant stability. Med Oral Patol Oral Cir Buccal. 2011;16:62-7.

2. Veltri M, Balleri B, Goracci C, Giorgetti R, Balleri P, Ferrari M. Soft bone primary stability of 3 different miniscrews for orthodontic anchorage: a resonance frequency investigation. Am J Orthod Dentofacial Orthop. 2009;135:642-8.

3. Gonzalez-Garcia R, Monje F, Moreno-Garcia C. Predictability of the resonance frequency analysis in the survival of dental implants placed in the anterior nonatrophied edentulous mandible. Med Oral Patol Oral Cir Buccal. 2011;16:664-9.

4. Albrektsson T, Dahl E, Enbom L, Engevall S, Engquist B, Eriksson AR, et al. Osseointegrated oral implants. A Swedish multicenter study of 8139 consecutively inserted Nobelpharma implants. J Periodontol. 1988;59:287-96.

5. Meredith N, Alleyne D, Cawley P. Quantitative determination of the stability of the implant-tissue interface using resonance frequency analysis. Clin Oral Implants Res. 1996;7:261-7. 
6. Penarrocha-Diago MA, Maestro-Ferrin L, Demarchi CL, Pennarocha-Oetra D, Pennarocha-Diago $M$. immediate versus non immediate placement of implants for full arch fixed restorations: A preliminary study. J Oral Maxillofac Surg. 2011;69:154-9.

7. Marković A, Calasan D, Colić S, Stojčev-Stajčić L, Janjić B, Mišić T. Implant stability in posterior maxilla: bone-condensing versus bone-drilling: a clinical study. Oral Surg Oral Med Oral Pathol Oral Radiol Endod. 2011;112:557-63.

8. Mandić B, Lazić Z, Marković A, Mandić B, Mandić M, Djinić A. et al. Influence of postoperative low-level laser therapy on the osseointegration of self-tapping implants in the posterior maxilla: a 6-week split-mouth clinical study. Vojnosanit Pregl. 2015;72:233-40.

9. Herrero-Climent M, Albertini M, Rios-Santos JV, Lázaro- Calvo P, Fernández-Palacín A, Bullon P. Resonance frequency analysis-reliability in third generation instruments: Osstell mentor ${ }^{\circledR}$. Med Oral Patol Oral Cir Bucal. 2012;17:801-6.

10. Kim JM, Kim SJ, Han I, Shin SW, Ryu JJ. A comparison of the implant stability among various implant systems: clinical study. J Adv Prosthodont. 2009;1:31-6.

11. Al-Jetaily S, Al-dosari AA. Assessment of Osstell and Periotest systems in measuring dental implant stability (in vitro study). Saudi Dent J. 2011;23:17-21.

12. Sennerby L, Roos J. Surgical determinants of clinical success of osseointegrated oral implants: a review of the literature. Int J Prosthodont. 1998;11:408-20.

13. Convissar RA. The biologic rationale for the use of lasers in dentistry. Dent Clin N Am. 2004;48:771-94.

14. Khadra M, Kasem N, Haanaes HR, Ellingsen JE, Lyngstadaas SP. Lyngstadaas SP. Enhancement of bone formation in rat calvarial bone defects using low-level laser therapy. Oral Surg Oral Med Oral Pathol Oral Radiol Endod. 2004;97:693-700.

15. Pinheiro ALB, Junior FAL, Gerbi MEM, Ramalho LMP, Marzola C, Ponzi EAC. Effect of Low Level Laser Therapy on the Repair of Bone Defects Grafted with Inorganic Bovine Bone. Braz Dent J. 2003;14:177218.

16. Petri AD, Teixeira LN, Crippa GE, Beloti MM, de Ooliveira PT, Rosa AL. Effects of Low-Level Laser Therapy on Human Osteoblastic Cells Grown on Titanium. Braz Dent J. 2010;21:491-8.

17. Kotz S, Balakrishnan N, Read CB, Vidakovic B. Encyclopedia of statistical sciences. 2nd ed. Hoboken, NJ: Wiley-Interscience; 2006.

18. Kirkpatrick LA, Feeney BC. A simple guide to IBM SPSS statistics for version 20.0. Student ed. Belmont, Calif.: Wadsworth, Cengage Learning; 2013.

19. Glavind L, Loe H. Errors in the clinical assessment of periodontal destruction. J Periodont Res. 1967;2:180-9.

20. Branemark P, Zarb G, Albrektsson T. Tissue-integrated prostheses. Chicago: Quintessence; 1985. p 11-43.

21. Herrero-Climent $\mathrm{M}$, Albertini $\mathrm{M}$, Rios-Santos JV, Lázaro- Calvo P, Fernández-Palacín A, Bullon P. Resonance frequency analysis-reliability in third generation instruments: Osstell mentor ${ }^{\circledR}$. Med Oral Patol Oral Cir Bucal. 2012;17:801-6.

22. Walsh LJ, Goharkhay K, Verheyen P, Moritz A. Low Level Laser Therapy. (LLLT) in Moritz A. Oral Laser Application. Quintessenz Verlags-Gmbh. 2006;521-39.
23. Strbac GD, Unger E, Donner R, Bijak M, Watzek G, Zechner W. Thermal effects of a combined irrigation method during implant site drilling. A standardized in vitro study using a bovine rib model. Clin Oral implants Res. 2012;25:665-74.

24. Lee J, Ozdoganlar OB, Rabin Y. An experimental investigation on thermal exposure during bone drilling. Med Eng Phys. 2012;34:1510-20.

25. Augustin G, Davila S, Udilljak T, Staroveski T, Brezak $\mathrm{D}$, Babic S. Temperature changes during cortical bone drilling with a newly designed step drill and an internally cooled drill. Int Orthop. 2012;36:1449-56.

26. Martin E. Lasers in dental implantology. Dent Clin N Am. 2004;48:999-1015.

27. McKinney RV, Koth DL, Steflik DE, Robinson FG, Davis BC, Morris CF, et al. Crystal sapphire. Endosteal dental implants in humans: Ten years results. J Oral Implantol Res. 1967;2:180-6.

28. Ersanli S, Karabuda C, Beck F, Leblebicioglu B. Resonance frequency analysis of one-stage dental implant stability during the osseointegration period. J Periodontol. 2005;76:1066-71.

29. Zix J, Kesiler-Liechti G, Mericska-Stern R. Stability measurements of one-stage implants in the maxilla by means of resonance frequency analysis- a pilot study. Int J Oral Maxillofac Implants. 2005;20:747-52.

30. García-Morales JM, Tortamano-Neto P, Todescan FF, de Andrade JC Jr, Marotti J, Zezell DM. Stability of dental implants after irradiation with an 830-nm lowlevel laser: a double-blind randomized clinical study. Lasers Med Sci. 2012;27:703-11.

31. Sennerby L, Meredith N. Implant stability measurements using resonance frequency analysis: biological and biomechanicalaspects and clinical implications. Periodontol 2000. 2008;47:51-66.

32. Aparicio C, Lang NP, Rangert B. Validity and clinical significance of biomechanical testing of implant/bone interface. Clin Oral Implants Res. 2006;17 (Suppl 2):27.

33. Karl M, Graef F, Heckmann S, Krafft T. Parameters of resonance frequency measurement values: a retrospective study of 385 ITI dental implants. Clin Oral Implants Res. 2008;19:214-8.

34. Sun G, Tuner J. Low-level laser therapy in dentistry. Dent Clin N Am. 2004; 48: 1061-76.

35. Kim JR, Kim SH, Kim IR, Park BS, Kim YD. Lowlevel laser therapy affects osseointegration in titanium implants: resonance frequency, removal torque, and histomorphometric analysis in rabbits. J Korean Assoc Oral Maxillofac Surg. 2016;42: 2-8.

36. Khadra M. The effect of low level laser irradiation on implant tissue interaction: in vivo and in vitro studies. Swed Dent J Suppl. 2005;172:1-6.

37. Guzzardella G, Torricelli P, Nicoli-aldini N, Giardino R. Osseointegration of endosseous ceramic implants after postoperative low power laser stimulation: an in vivo comparative study. Clin Oral Implants Res. 2003;14:226-32.

38. Pereira CL, Sallum EA, Nociti FH Jr, Moreira RW. The effect of low-intensity laser therapy on bone healing around titanium implants: a histometric study in rabbits. Int J Oral Maxillofac Implants. 2009;24:47-51. 